\title{
EDUCAÇÃO ESCOLAR E EDUCAÇÕES INDÍGENAS: REFLEXÕES EPISTÊMICAS
}

Odair Giraldin ${ }^{1}$

\section{RESUMO}

Neste texto apresento algumas reflexões para pensar sobre bases epistêmicas para uma educação escolar ligada aos povos indígenas. Reitero inicialmente que é preciso construir uma perspectiva baseada na pluralidade e na multiculturalidade com foco nas especificidades linguísticas e culturais de cada povo indígena. A partir dessa base, em que se valoriza o conhecimento dos regimes ontológicos, das filosofias e saberes ameríndios, podemos então perspectivar a interculturalidade (entendida como campo resultante da interação entre um povo com os não-indígenas e com outros povos indígenas). E, assim, podemos pensar em educações indígenas, uma vez que valorizamos a especificidade local de cada povo indígena. Nessa base, podemos finalmente refletir sobre políticas de educação escolar direcionadas aos povos indígenas.

PALAVRAS-CHAVES: Episteme. Ontologia. Educação. Multi/ interculturalidade.

\section{ABSTRACT}

In this text I present some reflections to think about epistemic bases for a school education linked to indigenous peoples. I reiterate that it is necessary to build a perspective based on plurality and multiculturalism, focusing on the linguistic and cultural specificities of each indigenous people. From this base, where the knowledge of the ontological regimes, of the Amerindian philosophies and knowledge, is valued, we can then envisage interculturality (understood as the field resulting from the interaction between a people with non-indigenous peoples and other indigenous peoples). And so we can think of indigenous education, since we value the local specificity of each indigenous people. On this basis, we can finally reflect on school education policies directed at indigenous peoples.

KEYWORDS: Episteme. Ontology. Education. Multi / interculturality.

1 Doutor em Antropologia pela Universidade de Campinas (Unicamp). Professor na Universidade Federal do Tocantins e coordena o Núcleo de Estudos e Assuntos Indígenas (NEAI). Coordenador Adjunto da Ação "Saberes Indígenas na Escola". Porto Nacional, TO, Brasil. E-mail: giraldin@uft.edu.br. 


\section{Introdução}

Muito tem sido escrito sobre povos indígenas no Brasil, na mesma proporção com que se escreveu sobre educação escolar indígena. Porém, há mais sobre a educação escolar que sobre a educação indígena, ou melhor, sobre as educações indígenas. Eu prefiro utilizar a expressão no plural (educações indígenas) para enfatizar a pluralidade étnica e cultural existente no Brasil (e no mundo) e marcar a característica multicultural dessa pluralidade.

Um primeiro ponto a ser ressaltado numa reflexão sobre bases epistêmicas para a educação escolar baseada nos saberes indígenas é a pluralidade. Singularizar nossa abordagem e pensar em educação indígena nos levaria a uma ilusão de conhecimento acreditando que todos os povos indígenas teriam um mesmo processo de socialização de seus membros visando à transmissão dos valores éticos e morais fundamentais para a existência de seus coletivos. Penso, ao contrário, que existem processos próprios de ensino e aprendizagem tão plurais, quanto são os povos indígenas que vivem no Brasil.

Outro ponto a considerar refere-se aos regimes ontológicos diversos possibilitados por essa pluralidade. Refiro-me a regimes ontológicos para expressar aquela característica presente na cosmologia de diversos povos indígenas em não realizar as mesmas separações entre humanos e não humanos ou entre natureza e cultura, tal qual se realiza no pensamento ocidental. $\mathrm{Na}$ ontologia religiosa do cristianismo, por exemplo, os humanos se opõem radicalmente aos animais, sendo os animais criados no quinto (aves e animais aquáticos) e no sexto dias (animais terrestres, além do homem e a mulher).

Assim, desde sempre humanos se distinguem totalmente dos animais vez que os primeiros teriam sido criados à imagem e semelhança do Criador (Genesis, caps. 1 e 2). Já na ontologia científica ocidental há uma relação de continuidade animal nos humanos, mas eles são considerados ex-animais, devido ao processo de evolução humana a partir de primatas ancestrais. Nessa ontologia, a inserção da cultura (restrita aos humanos), os distingue dos outros animais. Mas, para a maioria dos povos indígenas, os animais é que são exhumanos, pois são resultados de transformações que ocorreram devido à quebra de alguma regra social, em algum momento do processo histórico vivido por cada povo. 
Nessas ontologias ameríndias há diferenças radicais de explicação do mundo, de tal forma que precisamos aceitar que não vemos (todos nós, os Humanos) o mesmo mundo de formas diferentes (o que seria uma característica do relativismo), mas que cada regime ontológico vê mundos diferentes (o que seria uma abordagem perspectivista).

É por essa razão que, refletindo sobre os limites da episteme, Cesarino (2012) afirma que:

Essas e outras leituras de diversos estudos dedicados aos limites da episteme moderna mostraram, assim, que a compreensão das especificidades de tradições orais ameríndias (e de seus critérios de pensamento) não estaria apenas na capacidade de comunicação entre línguas tao distinta entre si como o português e o bororo, mas também, e mais fundamental, na passagem entre distintos regimes ontológicos (CESARINO, 2012, p. 75)

Portanto, ao nos debruçarmos sobre as educações indígenas e as políticas e ações voltadas à educação escolar indígena, temos que levar em consideração a especificidade linguística, cultural e ontológica de cada povo e não os tratar de forma generalizante. Dessa forma, mais eficaz que a noção de interculturalidade, será a noção de multiculturalidade. Deve-se partir desta para aquela ao pensarmos a relação entre ontologias distintas (as ameríndias e a ocidental). Voltarei a isso na conclusão.

Antes, pretendo apresentar alguns outros pontos de reflexão etnográfica que considero importantes para serem considerados para essa reflexão sobre as bases epistêmicas para pensar a educação escolar baseada nos saberes indígenas.

\section{Holismo}

Para pensar uma base epistêmica sobre a educação escolar baseada nos saberes indígenas e nas suas formas de aprender e ensinar, é preciso considerar a qualidade holística que perpassa as cosmologias dos povos indígenas. Para os povos ameríndios, o universo não é pensado como um todo composto de esferas disjuntivas como se expressa no pensamento ocidental (religioso e científico). Por isso, enquanto pensamos em reino vegetal e utilizamos esse 
termo para separar as plantas dos animais, colocados no reino animal e separamos ambos do reino mineral, nas cosmologias ameríndias esses elementos do mundo estão todos interligados e, por isso, não há uma separação categórica entre eles.

Ainda que entre os Timbira haja um termo para terra (pjê entre os Timbira Orientais, pika em Apinajé), não há um termo para plantas no geral, nem para animais. E essa não separação ontológica se dá exatamente porque os seres que existem no universo são pensados como sujeitos.

É certo que os povos ameríndios não confundem uma árvore com uma anta. No entanto, atribuem a ambos uma mesma capacidade agentiva, pois árvore e anta são sujeitos, têm volição e comunicabilidade. Portanto, com capacidade de ocupar um determinado ponto de vista, uma perspectiva.

\section{Perspectivismo}

Essa capacidade de assumir um determinado ponto de vista bem como a qualidade subjetiva é atribuída a todos os seres que vivem no universo, desde os astros (Sol e Lua desceram à terra e a formaram com suas ações [mitos Timbira], Caxekwyj [Timbira] e Tainahakỳ [Karajá] desceram do céu e ensinaram os humanos a utilizar as plantas cultivadas), passando pelos animais (o rato ensinou os Kisedjê e os Kayapó a utilizarem o milho, os urubus e gaviões curaram Hartãte e ensinaram a técnica do xamanismo [Krahô] e festa do Pep-cahàc [Ràmkôkamẽkra e Apãnjekra/Canela) e as plantas (as abóboras e as batatas que fizeram a festa da batata e a ensinaram os $m \tilde{e} \tilde{\imath}$ [Krahô], ou as árvores que ensinaram seus poderes curativos para as pessoas [Ràmkôkamẽkra/Canela]). Entre os Ràmkòkamẽkra/ Canela, uma forma vocativa para chuva é mẽ pahkrit-xwyjê. Este termo liga-se a uma situação em que um grupo de jovens estava na habitação tradicional dos Pep-cahàc, localizada fora do círculo de casas da aldeia. Eles contam que num dia que ameaçava chuva forte, ninguém se importou em cuidar do grupo de jovens. Após ter passado a tempestade, foram até a casa dos Pep-cahàc mas não encontraram nenhum dos jovens lá. Eles haviam sido carregados pela chuva. Por isso, referem-se e relacionam- se intersubjetivamente com a chuva como uma turma de jovens, chamando a chuva por esse termo respeitoso que indica relação de amizade formal (SOARES, 2015, p. 141, nota 41). 
Mesmo sem conhecimentos linguísticos específicos, arriscome a dizer que a maneira como se expressam em português para se referirem a alguns elementos e situações, demonstram isso.

Exemplo - 1) Quando ocorre uma queda da tora durante uma corrida, não se afirma: "Eu cai com a tora", como dizemos em português, mas sim "A tora me derrubou". Isso porque se atribui à tora a capacidade de sujeito, de agente. Lembro-me de uma conversa com meu hôpĩ (Dodanim Piikẽn, da aldeia Manuel Alves), quando ele me contou que quando era jovem, uma vez a tora o derrubou e o feriu. Então, ele recorreu aos tratamentos que eram com lapadas de folhas nas pernas e nas costas. Uma pessoa olhando de fora poderia ver isso como um castigo por ele ter derrubado a tora, mas para os Krahô era um tratamento para se fortalecer porque aquela queda foi um indicativo de que se ele não se fortalecesse a tora continuaria a derrubá-lo e poderia o ferir seriamente.

Exemplo - 2) Também ouvi do meu hôpĩ numa viagem da Pedra Branca para a Manuel Alves, ele me dizer em português que "a chuva choveu". Em português, não falamos isso exatamente como não dizemos "o trovão trovejou" ou o "vento ventou". E não o falamos assim porque nossa cosmologia não perspectiva não atribuiu aos fenômenos da natureza, sobretudo os climáticos, a capacidade de agentes com subjetividades. Mas para as línguas indígenas, faladas por povos que tem essa cosmologia holística e atribuindo capacidade agentiva a todos os seres, é perfeitamente adequado dizer que a chuva choveu, ou que o trovão trovejou ou que o vento ventou, ou que a tora me derrubou ou que a doença me pegou.

\section{Corpo e Pessoa}

Assim, pensando numa base epistêmica para a educação escolar baseada nos saberes indígenas, precisamos compreender também a importância do corpo e da pessoa nas várias cosmologias ameríndias. A visão holística nelas presentes concebe uma potencialidade transformacional entre os seres. Veja-se que no início dos tempos todos, os seres eram humanos, sendo que os humanos atuais são os que continuaram com os mesmos corpos, enquanto que os animais atuais são ex-humanos (exemplo dos Inỹ em que 
Tainahakỳ provocou transformações de humanos em animais; dos Akwẽ e o casal de velhos que se transformou em padi [tamanduábandeira]; da história do tutule dos Apinaje, em que as crianças se transformaram em pássaros). É importante salientar a qualidade corpórea porque o ponto de vista se dá a partir do corpo. Mas o corpo deve ser compreendido não enquanto as características fisiológicas de um ser, mas corpo enquanto um conjunto de "afetos e afecções ou capacidades que singulariza cada espécie de cada espécie de corpo: o que ele come, como se move, como se comunica, onde vive, se é gregário ou solitário..." (VIVEIROS DE CASTRO, 1996, p. 128).

Então, é preciso cuidar dessa capacidade corporal desde o nascimento atuando-se para que ele tenha a agentividade humana. Por isso, as mulheres Kayapó modelam as cabeças dos bebês recémnascidos para terem o formato humano adequado. Ou então, como faziam os Kambeba, que moldavam os crânios deformando-os para terem a aparência humana concebida. É por isso que não se pode pintar as crianças pequenas Xerente com pinturas corporais clânicas, mas apenas com pintura de $h u k u$ (onça). Por isso, também, a realização dos resguardos corporais que os pais devem fazer, evitando-se diversas comidas ou ações enquanto as crianças são muito pequenas. É em função disso, ainda, que podemos compreender a festa do mel entre os Inỹ quando se oferece o primeiro mel para o bebê, como forma de agenciá-lo na humanidade.

Por isso, os investimentos em reclusões como o Ihkrere dos Krikati e Gavião, ou o Ketuwajê e Pepjê dos Ràmkôkamẽkra e Apãnjekra/Canela, períodos nos quais se investe na formação corpórea dos noviços e noviças, para que seus corpos aprimorem, paulatinamente, a condição humana adequada e definida pelas suas cosmologias. Todos esses investimentos no corpo e na sua formação objetivam formar as pessoas adequadas para manterem-se enquanto plenamente humanos e conservarem esse ponto de vista, essa perspectiva (o que se faz necessário para ser mẽhĩ, panhĩ, akwẽ, inỹ) e capazes de desempenhar papeis como membros de sua sociedade. 


\section{Coletividade}

Precisamos pensar a partir da coletividade ao refletir sobre o processo de aprender e ensinar. Sempre nos acostumamos e naturalizamos que o processo de aquisição de conhecimento se dá numa relação entre ensino e aprendizagem. Ou seja, enfatizamos que haja alguém habilitado e competente para ensinar e um conjunto de pessoas sem esses conhecimentos e com capacidade para aprender. Essa relação coloca a autoridade pedagógica na figura do professor que deve assumir uma postura hegemônica e de autoridade para exercer seu cargo de professor. Entre os Timbira e os Akwẽ o processo se dá mais no sentido inverso: tudo se passa em processo de aprender e ensinar.

O passo inicial é a existência de alguém com desejo de aprender e que manifeste esse desejo para um mestre que possa lhe ensinar. Através de um processo prático, o aprendiz será conduzido a aprender, a experienciar e iniciar o processo de relacionamento com os conhecimentos. Ressalto a palavra experienciar, porque de fato não podemos entender os conhecimentos como um conjunto de coisas (ainda que imateriais) que possam existir independentemente da experiência de cada pessoa. Conhecer, para a maioria dos povos indígenas, é experimentar no corpo as transformações necessárias para exercer as atividades de cada especialidade de saber (Coelho, 2016).

Por isso, o desejo de aprender e sua execução através do processo prático ensejam uma relação holística, dialógica e menos violenta da aprendizagem. Frequentemente, é comum verificarmos grupos de pessoas debatendo um determinado assunto e chegando a alguma consensualidade sobre o mesmo. Isso é o que ocorre frequentemente no pátio Timbira ou na casa de Wyhty. Ou dialogando coletivamente sobre histórias ou sobre locais de caça ou locais de roça. Isso significa que o processo de aprendizagem, e podemos estender isso, sobretudo, ao processo escolar, não é visto como resultado de um esforço individual e solitário de aquisição do conhecimento, mas sim, fruto de um processo coletivo, dialógico que permite a interlocução e a aprendizagem pela prática.

Há, porém, possibilidade de aprendizagem individualizada, sobretudo quando se dá pela aquisição de conhecimento através do contato com seres cosmológicos. Vamos citar alguns exemplos. Os Akwẽ que adquirem conhecimentos sobre músicas, por exemplo, através dos sonhos, que são momentos de viagens oníricas da alma, 
que pode deixar o corpo, temporariamente, durante o sono ou em caso de enfermidade. Há também possibilidade de aprendizagem pela interlocução entre seres espirituais e seres humanos, como no caso de aquisição de capacidade xamânica quando se entra em contato com seres espirituais do universo animal, vegetal ou mineral. Esse é um dos objetivos dos resguardos, por reclusão, entre os Ràmkôkamẽkra e Apãnjekra/Canela, ou no sofrimento dos jovens Xavante no ritual de Wai'a Rini e sua capacidade de ver através dos sonhos (Tserehahu, 2001). Há também possibilidade de alguém aprender conhecimentos a partir do contato individual com os espíritos. Ouvi um exemplo entre os Ràmkôkamẽkra/Canela que um rapaz recebeu os conhecimentos do mẽ karõ (parte espiritual) de uma árvore, depois que a tora o derrubou e o machucou. Ao andar pelo cerrado, caçando, ele ouviu o mẽ karõ de uma árvore dizendo a ele que a enfermidade dele poderia ser curada usando a parte interna da casca da árvore.

\section{Considerações finais}

Penso que para refletirmos sobre as bases epistêmicas para a educação escolar, devemos partir da pluralidade. Precisamos pensar, inicialmente, que há uma grande diversidade de epistemes, filosofias e ontologias em convívio na contemporaneidade. E reconhecer essa diversidade não é tarefa pouca. Sobretudo porque somos e estamos (nós brasileiros, não indígenas) em um regime ontológico e epistêmico que, tradicionalmente, negou validade ou mesmo negouse a reconhecer e conceber que houvesse outros regimes ontológicos ou epistêmicos, distintos do ocidental. E replicamos isso através do nosso processo educacional que trata a diversidade cultural de forma generalizante, imergindo paulatinamente as crianças nessa negação.

A partir dessa compreensão plural é que podemos buscar conhecer e compreender cada regime ontológico particular para, a partir dele, podermos compreender como esse povo em particular relaciona-se com o nosso regime ontológico e, como consequência, com nossa educação escolar. Por isso, a interculturalidade, entendida como o campo no qual se conjugam o mundo de cada povo indígena e de suas interações com os não-indígenas e também com outros povos indígenas, deve derivar da multiculturalidade, ou seja, a valorização focada na especificidade de cada cultura, filosofia e regime ontológico particular. 
Acredito que uma interculturalidade nascida a partir da multiculturalidade torna-se muito mais condizente com o respeito que se deve ter com cada povo indígena, em particular, e com suas ontologias, epistemes e educações próprias.

\section{Referências}

CESARINO, Pedro N. - Os relatos do Caminho-Morte: etnografia a e tradução de poéticas ameríndias. Estudos Avançados 26 (76), 2012.

SOARES, Ligia Raquel Rodrigues - "Eu sou o gavião e peguei a minha caça”. O ritual Pep-cahàc dos Ràmkôkamẽkra/Canela e seus cantos. Universidade Federal do Amazonas, Museu Amazônico, Programa de Pós-Graduação em Antropologia Social, 300 p. Tese (Doutorado) 2015.

SOUZA, Marcela S. Coelho - Conhecimento indigena e seus conhecedores: uma ciência duas vezes concreta. In CARNEIRO DA CUNHA, M.; CESARINO, P. N., Políticas Culturais e Povos Indígenas. SP, Editora UNESP, 2016.

TSEREWAHÚ, Divino - Wai'a Rini. O poder do sonho. Vídeo documentário, 114 min. 2001.

VIVEIROS DE CASTRO, Eduardo - Os pronomes cosmológicos e o perspectivismo ameríndio. MANA 2 (2):115-144, 1996.

Recebido para publicação em março de 2018.

Aceito para publicação em maio de 2018. 